\title{
Prevalence of Dental Caries and Its Relationship with Oral Hygiene and Type of Female Schools in Al-Kharj City, Kingdom of Saudi Arabia
}

\author{
Saad A Al Hazzani ${ }^{1}$, Entessar Z Alanazi ${ }^{2}$, Shaikha A Al Bejadi ${ }^{3}$, Maha A Al Wabil $^{4}$
}

\begin{abstract}
Objectives: The purpose of this study was to determine the prevalence of dental caries and its correlation with the oral hygiene status of 6 to 9-year-old school girls studying indifferent types of schools.

Materials and methods: A total of $(n=382)$ subjects were grouped into 4 clusters according to their school type (group 1 -Government School $(n=117)$, group 2-Holy Quran Memorization Schools $(n=62)$, group 3-Private School $(n=89)$ and group 4-Boosting Health $(n=$ 114). A single trained, and calibrated examiner recorded dental caries decayed missing filled teeth (DMFT index) by applying WHO diagnosis criteria. Plaque index and gingival index of the study participants were recorded and compared between the groups. All the data were analyzed by using statistical package for social sciences (SPSS) version 21. Descriptive statistics, one-way analysis of variance (ANOVA) and Pearson's correlation tests were applied.

Results: Government school students showed higher mean DMFT score (7.21), PI score (1.81) and gingival index score (1.97) followed by other schools. When mean DMFT scores were compared between the four types of schools no significant difference was found ( $p=0.39)$. On the contrary, the study showed significant differences in the mean Gl score $(p=0.04)$ and PI score $(p=0.049)$ between the four types of schools. DMFT score was found to be significantly correlated with the PI score $(r=0.225, p=0.000)$ and GI scores $(r=0.192, p=0.000)$. But DMFT did not show any significant correlation with the type of school.

Conclusion: This study indicated a high prevalence and severity of dental caries among 6 to 9-year school going female children from Al-Kharj city. Further; it revealed caries experience of the female students is significantly correlated with the plaque deposition on the teeth rather than the type of school. Hence there is a need to implement and evaluate oral health education and promotion programs targeted towards these students.

Keywords: Dental caries, DMFT, Gingival index, Kingdom of Saudi Arabia, Oral hygiene, Prevalence, Prevalence caries, Plaque index. Journal of Oral Health and Community Dentistry (2019): 10.5005/jp-journals-10062-0041
\end{abstract}

\section{INTRODUCTION}

$\mathrm{D}$ ental caries is a derogatory condition of the teeth which has grown to epic proportions in recent times and is now recognized by the WHO as a global pandemic. ${ }^{1}$ It is a multifactorial, infectious and irreversible condition of the teeth that are caused by demineralization of the inorganic components of the tooth and eventual destruction of the organic components. ${ }^{2}$ Worldwide, it is one of the most prevalent diseases affecting $60-90 \%$ of schoolaged children and a vast majority of adults. ${ }^{3}$ According to a WHO, higher DMFT values (an indicator of dental caries experience) are observed in most industrialized nations and some countries of Latin America while the developing countries of Asia and Africa display lower levels of dental caries experience. ${ }^{4}$ A study conducted on 6-year old's in Western Australia revealed that caries experience among that group of children increased from $27 \%$ in 1963 to $85 \%$ in $2005 .^{5}$ A retrospective analysis done on 5, 12 and 15-year-old children in India revealed that more than $40 \%$ children in India have shown dental caries in India in the past 15 years, both in the primary and permanent dentition. ${ }^{6} \mathrm{~A}$ cross-sectional study conducted on school children of 9 different towns in the city of Karachi in Pakistan ${ }^{7}$ revealed that the overall prevalence of dental caries among the studied sample was $69.9 \%$ with a mean DMFT score of $2.98 \pm 3.47$. A meta- analysis ${ }^{8}$ done to determine the prevalence of dental caries in the primary and permanent teeth of a 2 to 20 -year-old population in Arab League countries revealed that mean DMFT was 4.341 in primary teeth and 2.469 in permanent teeth. All these reports from various regions of the developing and developed world indicate
${ }^{1}$ Consultant. ${ }^{2}$ General Dentist, ${ }^{3}$ Dental Hygienist, ${ }^{4}$ Dental Assistant

${ }^{1}$ Department of Dental, King Khalid Hospital and Prince Sultan Center, Al-Kharj, Kingdom of Saudi Arabia

${ }^{2}$ Department of Dental, Al-Ajaji Dental Center, Riyadh, Kingdom of Saudi Arabia

${ }^{3}$ Department of Oral Health and Dental Hygiene Committee, Ministry of Health, Al-Kharj, Riyadh, Kingdom of Saudi Arabia

${ }^{4}$ Department of Dental, Al Saih Center of Primary Care, Al-Kharj, Riyadh, Kingdom of Saudi Arabia

Corresponding Author: Saad Al Hazzani, Consultant, Department of Dental, King Khalid Hospital and Prince Sultan Center, Al-Kharj, Kingdom of Saudi Arabia, e-mail: dr.saadalhazzani@gmail.com

How to cite this article: AL Hazzani SA, Alanazi EZ, Al Bejadi SA, Al Wabil MA. Prevalence of Dental Caries and Its Relationship with Oral Hygiene and Type of Female Schools in Al-Kharj City, Kingdom of Saudi Arabia. J Oral Health Comm Dent 2019;13(1):17-20.

Source of support: Nil

Conflict of interest: None

that dental caries is an established threat to the oral health of the world's population.

Several studies conducted in the Kingdom of Saudi Arabia to determine the prevalence of dental caries among children. One such study conducted on the primary and permanent teeth of children in the city of Dammam ${ }^{9}$ revealed that the overall prevalence of caries in both the primary and permanent teeth was $73 \%$ with $78 \%$ in the 6-9 year age group and 68\% in the 10-12 year age group.

(c) The Author(s). 20190pen Access This article is distributed under the terms of the Creative Commons Attribution 4.0 International License (http://creativecommons. org/licenses/by/4.0/), which permits unrestricted use, distribution, and non-commercial reproduction in any medium, provided you give appropriate credit to the original author(s) and the source, provide a link to the Creative Commons license, and indicate if changes were made. The Creative Commons Public Domain Dedication waiver (http://creativecommons.org/publicdomain/zero/1.0/) applies to the data made available in this article, unless otherwise stated. 
A cross-sectional study ${ }^{10}$ conducted in the city of Jeddah on children aged 9,10,11 and 12 years to observe the prevalence of caries in the first permanent molars. The results of this study highlighted that $67 \%$ of 9-year-olds had carious first molars and incidence increased to $70.5 \%, 82 \%$, and $83.5 \%$ in 10,11 and 12 -year-olds respectively. Another study ${ }^{11}$ conducted on pre-school children aged $3-5$ years in the city of Riyadh in 2016 concluded that the caries prevalence among the study sample was $69 \%$ with a mean DMFS score of 6.9 and a mean DMFT of 3.4. Researchers in the University Of Dammam College Of Dentistry conducted a meta-analysis ${ }^{12}$ on the prevalence of dental caries on the Saudi population and concluded that the mean DMFT was 5.38 in the primary and 3.34 in the permanent dentition. All these studies reveal that the caries prevalence in the Kingdom of Saudi Arabia is high. It is only natural that investigators must look into the causes of this high rate of caries prevalence within the Kingdom to develop dental public health strategies to combat this disease.

Dental caries is strongly linked to oral hygiene. A study was conducted in Mexico ${ }^{2}$ on low socio-economic pre-school children to determine their caries experience, and its association with oral hygiene revealed that $98.2 \%$ of children who had dental caries also had poor oral hygiene. Whereas only $1.8 \%$ of children with adequate oral hygiene showed signs of dental caries and those who had good oral hygiene comprised of only $0.17 \%$ with dental caries. Another study conducted in Oregon, United States ${ }^{13}$ on the oral hygiene behaviors and caries experience in northwest precedent patients concluded that the frequency of tooth-brushing using a fluoridated toothpaste and the presence of readily-visible heavy plaque were the factors most strongly associated with mean caries rate. In a Brazilian study ${ }_{1}^{14}$ caries experience was found to be more significantly common in children who had dental calculus or bleeding gums implying an association between plaque and gingival status and dental caries.

Al-Kharj, also known locally as Al-Saih, is a city in Al-Kharj Governorate in central Saudi Arabia. Al-Kharj is $77 \mathrm{~km}$ south to the capital city Riyadh. Children of Al-Kharj receive their education through different types of schools such as government schools, Holy Quran memorization schools, private schools, and healthboosting schools. These schools follow the different educational curriculum to teach students.

Previous studies from Kingdom of Saudi Arabia mainly reported the prevalence and severity of dental caries among private and government school children in different cities. However, these studies did not evaluate the relationship between school type and caries experience, and oral hygiene of the students. Hence the present study was conducted with the objectives to determine the prevalence of dental caries among school-going female children in Al-Kharj City, Saudi Arabia. Secondly to find out the correlation between caries experience, plaque accumulation and gingival conditions of female students across four types of schools.

\section{Materials and methods}

\section{Ethical Approval}

The study proposal was submitted to the research center of King Khalid Hospital, Al-Kharj and ethical approval were obtained (KKH/ IRB/2016/05). Prior permission was taken from the school authorities to visit the schools for conducting the study. Parents of the children were informed about the clinical oral examination of their child and consent was obtained. Additionally, oral informed consent to examine the mouth was obtained from the child.

\section{Study Design}

This was a descriptive, cross-sectional, analytical study conducted among 382 female school going students aged between 6-9 years in Al-Kharj city, Saudi Arabia. Study subjects were randomly selected from the attendance registers of 4 different types of schools (group 1-government school $(n=117)$, group 2-Holy Quran Memorization Schools ( $n=62$ ), group 3-private school ( $n=89)$ and group 4-Boosting health $(n=114)$ according to the inclusion and exclusion criteria. Inclusion criteria involved all girls between the ages of 6-9 years who attended these schools. All girls below the age of 6 or above the age of 9 years were excluded from the study. Any child with systemic health problems was excluded.

\section{Sample Size Calculation}

A sample size of 384 was calculated based on the assumption of the effect size of 0.20 , the alpha error probability of $0.05 \%$, power of the study 0.92 and the number of groups 4 for ANOVA test. The sample size calculation was performed by using the G-power 3.1 sample size calculator. However, two students withdrew from the final study thus a total sample size of 382 .

\section{Oral Examination}

Oral examination of the study participants was carried out in their respective schools. The girls were examined to record DMFT scores to assess caries experience in permanent teeth, plaque index (Silness and Loe) and gingival Index (Loe and Silness) were also noted. Recording of the indices was carried out by a single trained and calibrated examiner. Oral examination was performed by using WHO probe and mouth mirror under the natural light while student sitting in a regular chair. For every student type of school, age, DMFT score, plaque index score and gingival index scores were recorded and analyzed.

\section{Statistical Analysis}

All the data were analyzed by using SPSS version 21. Descriptive statistics of frequency distribution study participants in four types of schools was calculated. Mean scores ofDMFT index, plaque index, and gingival index were calculated and compared across the different groups by applying one-way ANOVA test. Pearson's correlation test was performed to assess the correlation between DMFT score other variables (type of school, $\mathrm{Gl}$ and PI). For all the statistical purposes a $p$ value of $(p<0.05)$ is considered significant.

\section{Results}

Out of a total 382 subjects, the largest sample size was observed from the government school $(n=117)$ whereas boosting health school children formed the second largest sample $(n=114)$ followed by $(n=89)$ and $(n=62)$ children were sampled from Private and Noble Quran Memorization Schools, respectively. The distribution of the sample across the four different school types is shown in (Table 1).

The prevalence of dental caries (94\%), plaque deposition (96.6\%) and gingival inflammation (96.6\%) were found to be very high amongst the female students studying in government schools compared to any other type of schools as shown in (Graph 1).

Descriptive statistics were used to calculate the means of the plaque index score, gingival index score and the DMFT status of the sample from each school. It was found that the sample from the Government School showed the highest mean values for all three parameters $(\mathrm{PI}=1.81, \mathrm{GI}=1.97$ and $\mathrm{DMFT}=7.21$ ). Children from the Noble Quran Memorization School exhibited 
Table 1: Distribution of study participants in different groups $(n=382)$

\begin{tabular}{lll}
\hline Groups & $n$ & $\%$ \\
\hline Government school & 117 & 30.6 \\
Holy Quran Memorization Schools & 62 & 16.2 \\
Private school & 89 & 23.4 \\
Boosting health & 114 & 29.8 \\
\hline
\end{tabular}

$(\mathrm{PI}=1.44 \mathrm{GI}=1.32$ and DMFT $=7)$ which is the second highest among the study sample. Similarly, the Boosting Health School $(\mathrm{PI}=1.77, \mathrm{GI}=1.55$, and $\mathrm{DMFT}=6.68)$ and Private schools $(\mathrm{PI}=1.72, \mathrm{Gl}=171$, and DMFT $=6.26)$ exhibited different scores as shown in (Graph 2). Comparison of PI scores between different group of schools showed a statistically significant difference ( $F=2.64, p=0.049)$ by one-way ANOVA. On further analysis with Tukey's multiple comparison test showed significant mean differences in plaque index scores between government schools and Holy Quran Memorization Schools.

Similarly, when GI scores were compared between different group of schools a statistically significant difference was observed $(F=9.49, p=0.000)$. Multiple comparison tests showed significant mean differences in Gl scores between government schools and Holy Quran Memorization Schools as well as between government schools and boosting health schools. However, the mean DMFT score did not differ significantly across different types of schools $(\mathrm{F}=0.99, p=0.397$ ) considered in the study as shown in (Table 2 ).

Plaque accumulation on the teeth was found to be a critical element as it showed a significant positive correlation with the gingival index score $(r=0.701, p=0.000)$ and caries experience among $(r=0.225, p=0.000)$ the studied subjects. On the contrary, no significant correlation was observed between plaque index scores and different types of female schools $(r=0.004, p=0.942)$ considered in the study. Pearson's correlation test did not show any

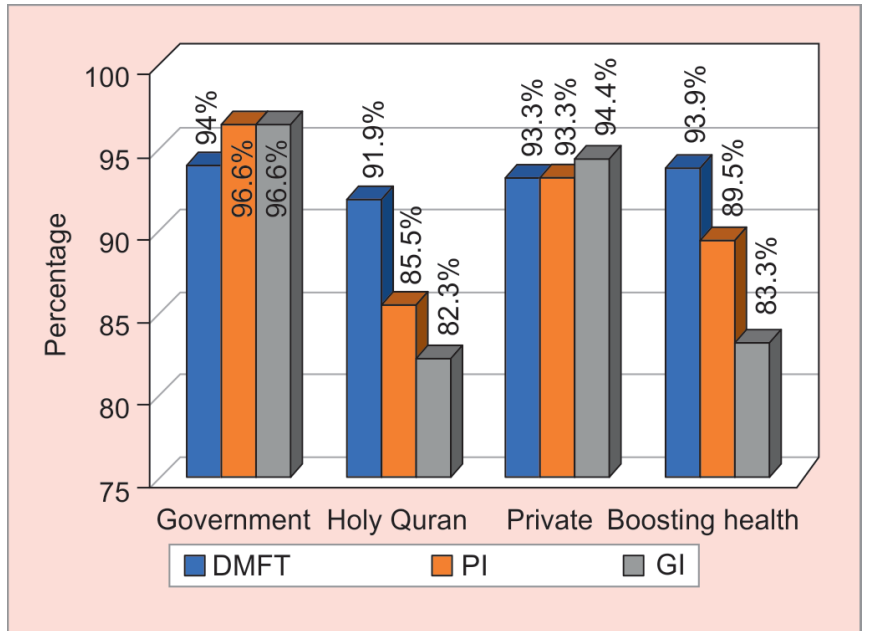

Graph 1: Prevalence of dental caries, plaque and gingival inflammation in study groups

significant correlation between DMFT score and different types of schools ( $r=-0.065, p=0.206)$. However, the DMFT score was found to be significantly correlated with the PI score $(r=0.225, p=0.000)$ and $\mathrm{Gl}$ scores $(r=0.192, p=0.000)$ as shown in (Table 3$)$.

\section{Discussion}

The results of this present study suggest that the highest caries prevalence and worst oral hygiene is found in children attending government schools. While the lower prevalence of dental caries was found in children attending private schools and children attending Noble Quran Memorization schools.

A special feature of this study was to include Boosting Health School as a separate cluster to examine whether children of this

Table 2: Comparison of $\mathrm{PI}, \mathrm{Gl}$ and DMFT scores among different group of schools

\begin{tabular}{|c|c|c|c|c|c|c|c|c|c|}
\hline \multirow[b]{2}{*}{ Index } & \multirow[b]{2}{*}{ Groups } & \multirow[b]{2}{*}{$N$} & \multirow[b]{2}{*}{ Mean } & \multirow[b]{2}{*}{$S D$} & \multirow[b]{2}{*}{$S E$} & \multicolumn{2}{|c|}{$95 \% \mathrm{Cl}$} & \multirow[b]{2}{*}{$F$} & \multirow[b]{2}{*}{$p$} \\
\hline & & & & & & $L B$ & $U B$ & & \\
\hline \multirow[t]{5}{*}{$\mathrm{PI}$} & Government & 117 & 1.81 & 0.85 & 0.08 & 1.66 & 1.97 & \multirow[t]{5}{*}{2.64} & \multirow[t]{5}{*}{0.049} \\
\hline & $\begin{array}{l}\text { Holy Quran } \\
\text { Memorization }\end{array}$ & 62 & 1.44 & 0.82 & 0.10 & 1.23 & 1.64 & & \\
\hline & Private & 89 & 1.72 & 0.85 & 0.09 & 1.54 & 1.90 & & \\
\hline & Boosting health & 114 & 1.77 & 1.00 & 0.09 & 1.59 & 1.96 & & \\
\hline & Total & 382 & 1.72 & 0.90 & 0.05 & 1.63 & 1.81 & & \\
\hline \multirow[t]{5}{*}{$\mathrm{Gl}$} & Government & 117 & 1.97 & 0.80 & 0.07 & 1.83 & 2.12 & \multirow[t]{5}{*}{9.49} & \multirow[t]{5}{*}{0.000} \\
\hline & $\begin{array}{l}\text { Holy Quran } \\
\text { Memorization }\end{array}$ & 62 & 1.32 & 0.83 & 0.10 & 1.11 & 1.53 & & \\
\hline & Private & 89 & 1.71 & 0.76 & 0.08 & 1.55 & 1.87 & & \\
\hline & Boosting health & 114 & 1.55 & 0.93 & 0.09 & 1.38 & 1.73 & & \\
\hline & Total & 382 & 1.68 & 0.86 & 0.04 & 1.59 & 1.77 & & \\
\hline \multirow[t]{5}{*}{ DMFT } & Government & 117 & 7.21 & 3.95 & 0.36 & 6.49 & 7.94 & \multirow[t]{5}{*}{0.99} & \multirow[t]{5}{*}{0.397} \\
\hline & $\begin{array}{l}\text { Holy Quran } \\
\text { Memorization }\end{array}$ & 62 & 7.00 & 4.64 & 0.59 & 5.82 & 8.18 & & \\
\hline & Private & 89 & 6.26 & 3.55 & 0.38 & 5.51 & 7.01 & & \\
\hline & Boosting health & 114 & 6.68 & 4.36 & 0.41 & 5.87 & 7.49 & & \\
\hline & Total & 382 & 6.80 & 4.11 & 0.21 & 6.39 & 7.21 & & \\
\hline
\end{tabular}

$\mathrm{PI}$, plaque index, $\mathrm{Gl}$, gingival index, DMFT, decayed missing filled teeth

$\mathrm{SD}$, standard deviation, $\mathrm{SE}$, standard error, $\mathrm{Cl}$, confidence interval, $\mathrm{LB}$, lower bound, $\mathrm{UB}$, upper bound 
Prevalence of Dental Caries and Its Relationship with Oral Hygiene and Type of Female Schools

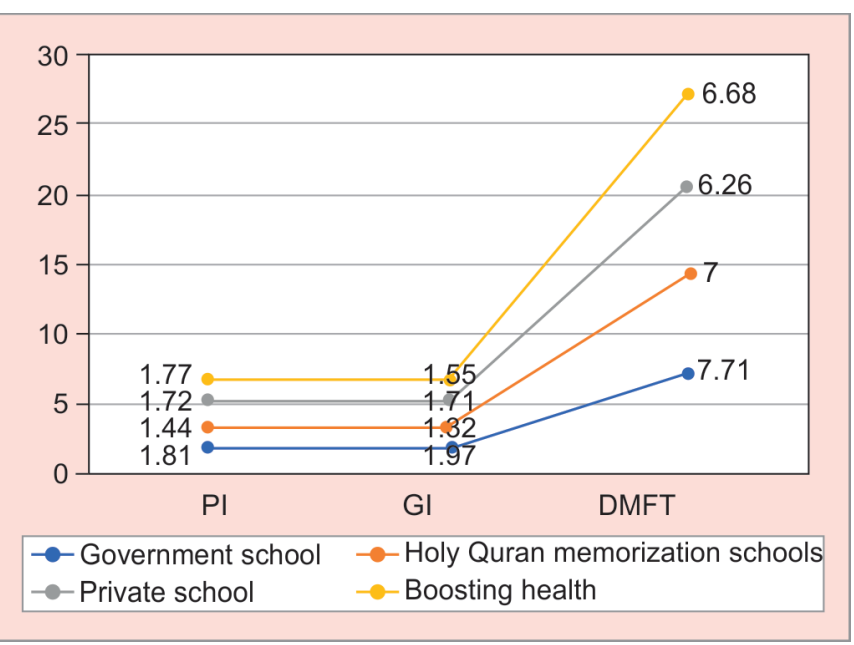

Graph 2: Mean Plaque index, gingival index and DMFT scores among study groups

school had better oral hygiene and lower DMFT scores as compared to other schools that did not implement basic preventive health programs. The overall results did not show any promising picture with high mean DMFT scores. Second highest mean GI scores were reported from this school as well as the third highest mean DMFT and mean $\mathrm{PI}$ scores. These revelations are unexpected from the Boosting Health School and indicate a shortcoming in preventive oral health programs which need to be further analyzed and addressed.

In the present study, plaque index is used to reflect the oral hygiene of the study participants. Statistical analysis revealed a significant positive correlation between caries experience and $\mathrm{PI}$ and Gl scores in all four groups of schools. But, caries experience did not show any significant correlation with the type of school.

The findings of the present study are fairly consistent with other studies conducted within Saudi Arabia with respect to caries status within the population studied. This present study revealed a high caries prevalence among the studied sample. A study conducted in the neighboring metropolis of Riyadh ${ }^{15}$ on 5 to 12 -year-old children of National Guard employees revealed a high level of dental caries among the studied sample along with a high level of general oral diseases. A similar study conducted on 12-year-old boys in the city of Madinah ${ }^{16}$ revealed a low caries prevalence (57.2\%), but a high mean $\mathrm{SiC}$ index. These results are in line with the present study.

The strength of this study lies in the fact that this present study explores the relationship between oral hygiene, dental caries and the type of school. The choice of four different school categories enables the researchers to get an idea about which categories of schools contain sample with the poorest oral hygiene and highest caries status. This study has some identifiable limitations. All analyses in this study were cross-sectional and the findings related to variables that do not necessarily translate into causative factors. The study was limited to a small segment of the young Saudi female students and, its results cannot be considered to be conclusively representative of the entire children of Saudi Arabia. Another important limitation is that decayed, missing and filled teeth (DMFT) were recorded only in permanent teeth thereby ignoring the caries experience primary teeth.

\section{Conclusion}

This study indicated a high prevalence and severity of dental caries among 6 to 9 -year school going female children from Al-Kharj city. Further, the caries experience of the female students is significantly
Table 3: Correlations between DMFT scores, $\mathrm{Pl}, \mathrm{Gl}$ and different study groups

\begin{tabular}{llll}
\hline Statistics & Groups & PI & GI \\
\hline Correlation coefficient & -0.065 & $0.225^{* *}$ & $0.192^{* *}$ \\
Sig. (2-tailed) & 0.206 & 0.000 & 0.000 \\
$\mathrm{~N}$ & 382 & 382 & 382 \\
\hline
\end{tabular}

**Correlation is significant at the 0.01 level (2-tailed)

correlated with the plaque deposition on the teeth rather than the type of school. Since boosting health schools in Saudi Arabia have already some preventive oral health program implemented efforts should be made to revise these programs. Also, to reduce caries incidence and to promote better oral hygiene preventive oral health programs should be initiated well before the school age.

\section{References}

1. Edelstein BL. The dental caries pandemic and disparities problem. BMC Oral Health 2006;6(Suppl 1):S2.

2. Frechero NM, Merino DD, Castaneira EC, et al. Dental caries experience and its relation to oral hygiene in Mexican children. Gac Med Mex 2015;151:455-459.

3. Stella YLK, Petersen PE, Pine CM, et al. Health-promoting schools: an opportunity for oral health promotion. Bulletin of the World Health Organization. 2005;83:677-685.

4. Petersen $\mathrm{PE}$, Bourgeois $\mathrm{D}$, Ogawa $\mathrm{H}$, et al: The global burden of oral disease and risks to oral health. Bulletin of the World Health Organization 2005;3: 661-669.

5. Christian B, Blinkhorn AS. A review of dental caries in Australian Aboriginal children: the health inequalities perspective. Rural and Remote Health (Internet) 2012;12:20-32.

6. Kundu H, Patthi B, Singla A, et al. Dental Caries Scenario Among 5, 12 and 15-Year-old Children in India-A Retrospective Analysis. Journal of Clinical and Diagnostic Research: JCDR. 2015;9(7):ZE01-ZE05.

7. Mohiuddin S, Nisar N, Dawani N. Dental Caries status among 6 and 12 Years Old School Children of Karachi City. J Pak Dent Assoc 2015; 24(1):39-45.

8. Khan SQ. Dental caries in Arab League countries: a systematic review and meta-analysis. Int Dent J 2014;64:173-180.

9. Farooqi FA, Khabeer A, Moheet IA, et al. Prevalence of dental caries in primary and permanent teeth and its relation with tooth brushing habits among schoolchildren in Eastern Saudi Arabia. Saudi Medical Journal 2015;36(6):737-742.

10. Al-Samadani KHM, Ahmad MS. Prevalence of first permanent molar caries in and its relationship to the dental knowledge of 9-12-year olds from Jeddah, Kingdom of Saudi Arabia. ISRN Dentistry 2012 (2012):391068.

11. Al-Meedani LA, Al-Dlaigan YH. Prevalence of dental caries and associated social risk factors among preschool children in Riyadh, Saudi Arabia. Pakistan Journal of Medical Sciences 32.2 (2016):452-456.

12. Khan SQ, Khan NB, Arrejaie AS. Dental caries. A meta-analysis on a Saudi population. Saudi Med J 2013;34:744-749.

13. Rothen M, Cunha-Cruz J, Zhou L, et al. Oral Hygiene Behaviors and Caries Experience in Northwest PRECEDENT Patients. Community dentistry and oral epidemiology 2014;42(6):526-535.

14. Freire MC, Reis SC, Fiqueiredo N, et al. Individual and contextual determinants of dental caries in Brazilian 12 year olds in 2010. Rev Saude Publica 2013;47(3):40-49.

15. Al-Banyan RA, Echeverri EA, Narendran S. Oral health survey of 5-12-year-old children of National Guard employees in Riyadh, Saudi Arabia. Int J Paediatr Dent. 2000;10(1):39-45.

16. Bhayat A, Ahmad MS. Oral health status of 12-year-old male schoolchildren in Medina, Saudi Arabia. East Mediterr Health J. 2014 Dec 17;20(11):732-737. 